\title{
Heat Processing and Change of Proper Indicators of Basalts
}

\author{
Rashidova R. K. ${ }^{1}$, Kurbanov A. A. ${ }^{1}$, Aliyev T. ${ }^{1}$, Jiyanov A. B. ${ }^{1}$, Turdieva O. J. ${ }^{1} \&$ Nurmatov J. T. ${ }^{2}$ \\ ${ }^{1}$ Navoi State Mining Institute, Galaba Street 127-a, Navoi City, Navoi region, Uzbekistan \\ ${ }^{2}$ Karshi Engineering Economics Institute, Mustakillik Street 225, Karshi City, Kashkadarya region, Uzbekistan \\ Correspondence: Kurbanov Abdirakhim Ahmedovich, Navoi State Mining Institute, 210100 Navoi City, Galaba \\ Street 127-a, Uzbekistan. Tel: 998-936-618-169. E-mail: bo_bosh@mail.ru
}

Received: March 13, 2020 Accepted: April 6, 2020 Online Published: September 2, 2020

\begin{abstract}
This paper presents the results of the analysis of the quality of basalts, their heat treatment and studies of changes in the chemical composition of basalts, which leads to a change in the external color of partially processed basalt raw materials (hereinafter referred to as semi-finished product). The results of a study of purified basalt from slime, impurities and hydroxides, changes in the chemical composition of basalt rock are presented.

The prospects of heat treatment of a semi-finished product and obtaining multi-colored products from mineral raw materials is shown. It was found that the optimal firing temperature of the semi-finished product, the possible options for changing the external color and the criterion points of the thermal effect at which the basalt semifinished product changes the external shade.

These statements are of great scientific and practical interest in the fact that during the heat treatment of a semifinished product, basalt easily overheats and gradually acquires a different color, which occurs to a liquids temperature and allows the future to plan to obtain high-quality multi-colored products from basalts, for example, products for design.
\end{abstract}

Keywords: research, process variable, roasting, basalt, rock, hardness, heat transfer, heat treatment, melting process, temperature, melting furnace, chemical composition

\section{Introduction}

In recent years, Uzbekistan's demand for new, cheap, competitive products from local raw materials has been growing, which are directly related to the expansion and development of the mining and metallurgical and processing industries. In such conditions, the solution of this problem is a very urgent problem and requires additional comprehensive research on the development of minerals.

In this case, we are talking about expanding the capacity of local basalt raw materials. The research results presented in this work are the results of studying the state of dry processed rock and obtaining crushed basalts, changing the properties and material composition of raw materials by heat treatment.

In the first stage of the study, the materials of domestic technical literature and the world were studied. Sufficient information was found on the casting of basalt rock. Sufficient information has been obtained related to the thermal effect on basalts, where the process ends with the melting of the rock and its melt.

There is information about the change in the intrinsic and material parameters of basalt rock during mechanical action on basalts, which are carried out by crushing, grinding, classification, pressing of the rock. However, no information was found about a change in the characteristic indicators of basalts by heat treatment, where the process ends with a change in the external shades of the raw material. [1-4].

The processing of raw materials, especially mineral rocks under the influence of thermal influences, is of great scientific and practical interest. In such cases, a specific feature of the rock, in particular basalts, is particularly distinguished. In this case, it is a question of the fact that the mineral during the heat treatment can experience targeted phase changes in the chemical composition, restoration of the structure and properties of the liquid or solid phase of the feed. In practice, basalt processing enterprises of Uzbekistan mainly produce basalt heatinsulating materials and fittings.

This circumstance is explained by poorly studied chemical and mineralogical composition, the possibility of this rock and the properties of basalt rock, as well as the lack of effective, innovative methods for obtaining basalt products and external investment. [3-5]. 
Currently, four methods of processing basalts are known in world practice, which are: a method for producing stone casting for fibers; sweeping operations to obtain a melt of metal substitutes; dissolving basalt fiber in acidic media to produce composites; obtaining products by dry processing. [3-6].

Most of the methods used in practice for determining the chemical composition of a substance are based on an analysis of the composition of solutions that contain certain elements. Such techniques are also used in the analysis of samples of inorganic origin (rocks, ores, minerals, shales, etc.). They are usually dissolved in acids or treated with various chemicals at high temperature.

A study of the production status and experience of processing basalt company, in Uzbekistan show that they are mainly engaged in the production of basalt crystalline heat-insulating materials. The reason for this is various objective and subjective arguments and facts that cannot be ignored. Therefore, at the moment, to improve existing situations and expand the area of use of basalts for organizing the production of new basalt products, it is advisable to use various non-traditional methods for processing basalts. In this case, it is proposed to obtain basalt products by heat treatment of the rock.

\section{Method}

Given the above, it is of scientific and practical interest to study the inherent and material state of basalts under the influence of thermal effects. To do this, we suggest using cleaned from sludge, impurities and hydroxides (hereinafter referred to as sludge), which adversely affect the quality of products. It is proposed to use refined, precrushed and ground raw materials. To show that raw materials in this state are easily subjected to heat treatment, are sensitive to thermal influences, and raw materials easily change their external shades.

According to the State Committee for Nature Protection, the degree of salinity of the irrigated lands of our Republic is high, including those lands where basalt deposits are located. These territories are: Namangan, Navoi, Tashkent, Jizzakh regions. The average salinity of the lands of Namangan Oblast reaches $28 \%$, Jizzakh Oblast $85.4 \%$ and Navoi Oblast $92.9 \%$ [1]. The facts show that basalts, untreated from sludge and salts, in a humid environment not only destroy the basalt processing equipment, but also spoil the products.

The study and analysis of the consequences of processing basalts and the use of heat-insulating materials obtained from raw basalt rock showed that they are prone to corrosion. It was found that, remaining in the rock and in the finished product, harmful impurities can easily come into contact with the environment or with a damp space and cause corrosion.

As a result, they become a reason for reducing the use of processing equipment and finished products. If we take into account that heat-insulating basalt products are used in power engineering, construction, road and automobile construction, etc., you can easily evaluate the effectiveness of their application. Therefore, the study of the influence of sludge on the process and on the quality of products also has an important scientific and practical interest. [2]

Experimental studies were carried out as follows. First, elements of the chemical composition of the rock of the Aydarkul deposit were studied. The results of the study in a summary form of data are presented in table 1 .

Table 1. Experimental data on the chemical composition of Aydarkul basalts, (in\%)

\begin{tabular}{|c|c|c|c|c|c|c|c|c|c|c|c|}
\hline $\begin{array}{c}\text { Title constituents } \\
\text { Chemical } \\
\text { elements }\end{array}$ & $\mathrm{SiO}_{2}$ & $\mathrm{TiO}_{2}$ & $\mathrm{Al}_{2} \mathrm{O}_{3}$ & $\mathrm{CaO}$ & $\mathrm{MgO}$ & $\mathrm{FeO}$ & $\mathrm{Fe}_{2} \mathrm{O}_{3}$ & $\mathrm{~K}_{2} \mathrm{O}$ & $\mathrm{Na}_{2} \mathrm{O}$ & $\mathrm{MnO}_{2}$ & Other \\
\hline Number (\%) & $43,7 \div 56,9$ & $1,5 \div 2,5$ & $, 2 \div 10,2$ & $5,4 \div 8,8$ & $2,7 \div 3,8$ & $4,6 \div 6,9$ & $2,9 \div 3,0$ & $0,14 \div 0,19$ & $2,8 \div 3,3$ & $1,09 \div 0,11$ & 4,89 \\
\hline
\end{tabular}

Comparison of the obtained data on the chemical composition of the basalts of the Aydarkul deposit with other deposits of Uzbekistan and foreign countries showed that these data are very different from each other. This at one time requires a special approach to the technological process of processing basalts. Significant amounts of such chemical compounds as $\mathrm{SiO}_{2}, \mathrm{CaO}, \mathrm{Al}_{2} \mathrm{O}_{3}$ are observed in the Aydarkul basalt rock. Such components as $\mathrm{MnO}, \mathrm{Fe}_{2} \mathrm{O}_{3}, \mathrm{FeO}$ in a percentage ratio are contained in a smaller amount in the basalt of the Aydarkul deposit than in other deposits of Uzbekistan. [2-3].

The results of the study show that an increase in the content of $\mathrm{Fe}_{2} \mathrm{O}_{3}, \mathrm{SiO}_{2}$, and $\mathrm{TiO}_{2}$ in the composition of basalts increases their melting point and decreases the casting properties of the melt. The density of the rock decreases, 
and it becomes more suitable for crushing and grinding. An increase in the resistivity of the cast product to external shocks is observed.

As noted above, an increase in the $\mathrm{SiO}_{2}$ content of basalts by more than $50 \%$, sometimes up to $60 \%$ and $\mathrm{TiO}_{2}$ to $2.5 \%$, which contributes to a decrease in viscosity, casting properties of the melt and melting of basalts will be unprofitable. Therefore, basalts with such a $\mathrm{SiO}_{2}$ content are easily crushed and milled.

The noted difference in the ratio of chemical elements in basalts can significantly affect their technological properties, not talking about inherent and material indicators. All these properties play an important role in determining the purpose and expansion of the range of products based on this breed.

Of particular interest in the processing of basalt rock is washing, which occurs after crushing of basalts, i.e. to the screening stage. For comparison, the amount of sludge on the basalts of Uzbekistan studied the state of basaltic rocks of the Aydarkul, Asmansai and Hawasai deposits. Basalt rock was washed according to the method of Professor A.A. Kurbanova on a washing machine - buter, which after disintegration is specialized for screening [2].

In this process, the rock after washing, is fed to medium crushing, i.e. after separation of large-sized basalts $250 \div$ $300 \mathrm{~mm}$ into smaller pieces (according to equipment specifications - $40 \mathrm{~mm}$ ). After the first stage of crushing the rock in the crusher, tightly adhered cemented layers may remain on the surface of the basalt rock, and in some cases traces of dirt.

To verify the effectiveness of the recommended cleaning method, an experiment was carried out to wash basalts from sludge. The experiment involved $200 \mathrm{~kg}$ of samples of basalts from research objects. The experiment was carried out as follows.

The results of the experiment are listed in table. 2 and are presented in Figure 1.

Table 2. Indicators of mechanical cleaning of basalts from the Gavasai deposits, Asmansai and Aydarkul

\begin{tabular}{lccc}
\hline & \multicolumn{3}{c}{ Field } \\
\hline The name of the indicators. & Gavasai & Asmansai & Aydarkul \\
The mass of the sample of basalts subjected to leaching, kg & 200 & 200 & 200 \\
The mass of the sample of basalts subjected to leaching, kg Mass of & 199,5 & 199,5 & 199,5 \\
basalts with a particle size of 5 6 mm, after crushing, kg & & & \\
Mass of basalts after washing, kg & 199,0 & 198,5 & 198,0 \\
Masses of basalts after washing, kg rel.\% From the original & 1,0 & 1,5 & 2,0 \\
\hline
\end{tabular}

In turn, all three rock samples were mechanically washed in the butter. After washing, all samples of basalt rock were dried. Studies show that after the crushing process, the mass of rock impurities extracted from every $200 \mathrm{~kg}$ was on average $0.5 \%$ (approximately $0.5 \mathrm{~kg}$ ) of the total mass. The change in rock mass after washing was $0.5 \%$. The mass of released sludge increases with increasing salinity of the soil in the field.

One of the properties of rocks is their porosity. Unlike other minerals in basalts, it rarely allows penetration of harmful impurities into the rock. It is noted that basaltic rocks are chemically stable and high strength. Therefore, basalt stone is rarely chemically cleaned. The analysis of basalts revealed that on the surface of individual pieces of basalt contains $\mathrm{NaCl}, \mathrm{KCl}, \mathrm{CaCl}_{2}, \mathrm{CaO}$, etc. formed in exogenous and hydrophobic natural processes that can be removed in the process of crushing (partially) and mechanical washing.

Thus, it was found that the ecological purity of basalts can be ensured only if the basalt rock is washed during the processing by mechanical cleaning. This method plays an important role in preventing the appearance of corrosion on the surface of the working bodies of processing machines.

To do this, rock samples were made in the form of tablets, which were then placed in the IR Tracer 100 SHUMADZU device in the wavelength region of $400 \div 4000 \mathrm{sm}-1$. Then the IR spectra were taken. The resulting spectrum is presented in figures $3 \mathrm{a}, \mathrm{b}$ and $\mathrm{c}$.

To study the interaction of various silicate compounds in the basalts of the Aydarkul deposit, the following reagents were used: 


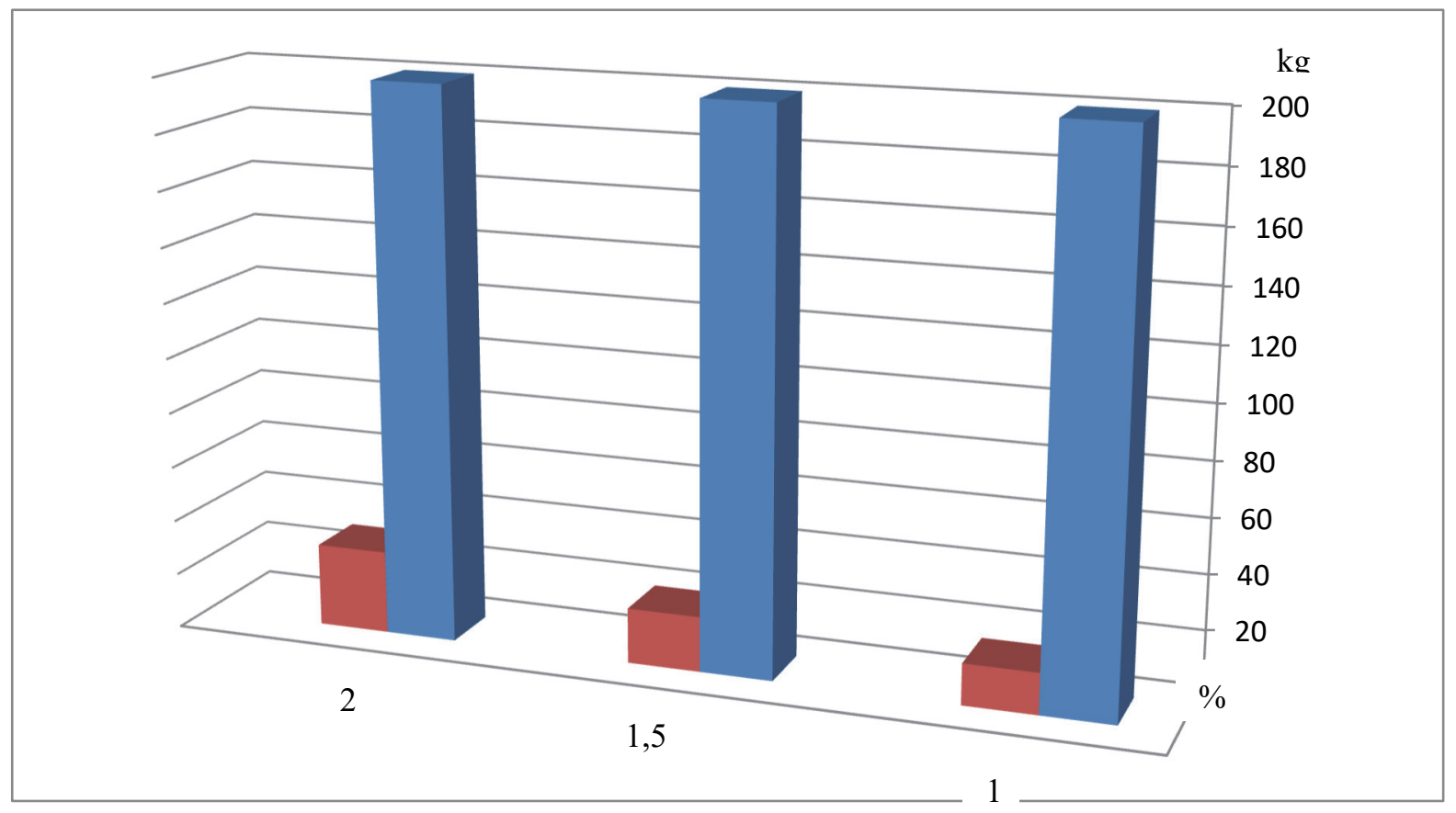

Figure 1. Indicators of mechanical cleaning of basalt deposits: "Gavasai", "Asmansai" and "Aydarkul"

A. acid - $\mathrm{HCl}, \mathrm{H}_{2} \mathrm{SO}_{4}, \mathrm{HNO}_{3}$;

B. base $-\mathrm{NaOH}, \mathrm{Ca}(\mathrm{OH})_{2}$;

C. salt- $\mathrm{AgNO}_{3}, \mathrm{BaCl}_{2}, \mathrm{CaCl}_{2}, \mathrm{~K} 4\left[\mathrm{Fe}(\mathrm{CN})_{6}\right]$.

An arbitrarily chosen mass of $-10 \mathrm{~g}$ basalt was mixed with distilled water, after 30 minutes a suspension formed. Then the suspension was filtered. In this process, a colloidal solution that was pale yellow was poured into another glass. Next, the sample using a Buchner funnel, which is designed to filter solutions, was filtered and decanted several times with distilled water. The second part of the precipitate was filtered and washed in the same way with water. Both precipitates were dried in an oven at a temperature of $60 \div 700 \mathrm{C}$.

Some qualitative reactions with the filtrate to ions were carried out: $\mathrm{Na}^{+2}, \mathrm{Mg}^{+2}, \mathrm{Ca}^{+2}, \mathrm{Fe}^{+2}$, etc. These ions are not found in solutions. This means that in this case, the transition of ions from the composition of basalts to solution did not occur.

Thus, the research results show that Aydarkul basalts have silicate and aluminosilicate impurities, which are separated in the form of a colloidal solution. Based on this, it can be concluded that before starting the heat treatment of basalt rock, it is necessary to rid them of sludge, clay impurities and hydroxides.

After obtaining high-quality (basalt-free sludge) experimental research was conducted on the thermal effect on the rocks and the study of structural changes in basalts. Therefore, the process of studying the thermal effect on the basalt semi-finished product, which is currently widely practiced in research, was carried out. [6-7, 8-10].

To study the structural change in basalts, we study the consequences of heat treatment of the rock, which is based on their inherent indicators. Investigation of the process of thermal influence on basalts, where the transformation of basalt rock occurs, the derivatives of the diagram shown in Figure 2 are taken. In this study, the Labybsys IVO device was used. Where the heating temperature reaches from $50^{\circ} \mathrm{C}$ to $1200^{\circ} \mathrm{C}$. At the same time, the heating rate is $50 \mathrm{C} / \mathrm{min}$.

Based on the obtained results of the derivatogram study, the samples were subjected to heat treatment at temperatures: $100,300,500,700,900,100$ and $1200^{\circ} \mathrm{C}$. For heat treatment, a muffle furnace was used.

The manifestation of the endothermic effect of the thermolysis process, which appears at a temperature of $80 \div$ $240^{\circ} \mathrm{C}$, was studied. They show the decomposition of clay impurities or the removal of hygroscopic water contained in the rocks.

In the future, at a temperature of $520^{\circ} \mathrm{C}$, fainting effects and an increase in an insignificant mass are observed, which corresponds to the interconversion of the basalt component. 
However, when the temperature reaches $820^{\circ} \mathrm{C}$, deep endothermic effects and mass losses of up to $16 \mathrm{mg}$ from an arbitrarily selected sample mass are observed (this is approximately $37.72 \%$ of the mass), which corresponds to the decomposition of carbonates and silicates contained in basalt rocks.

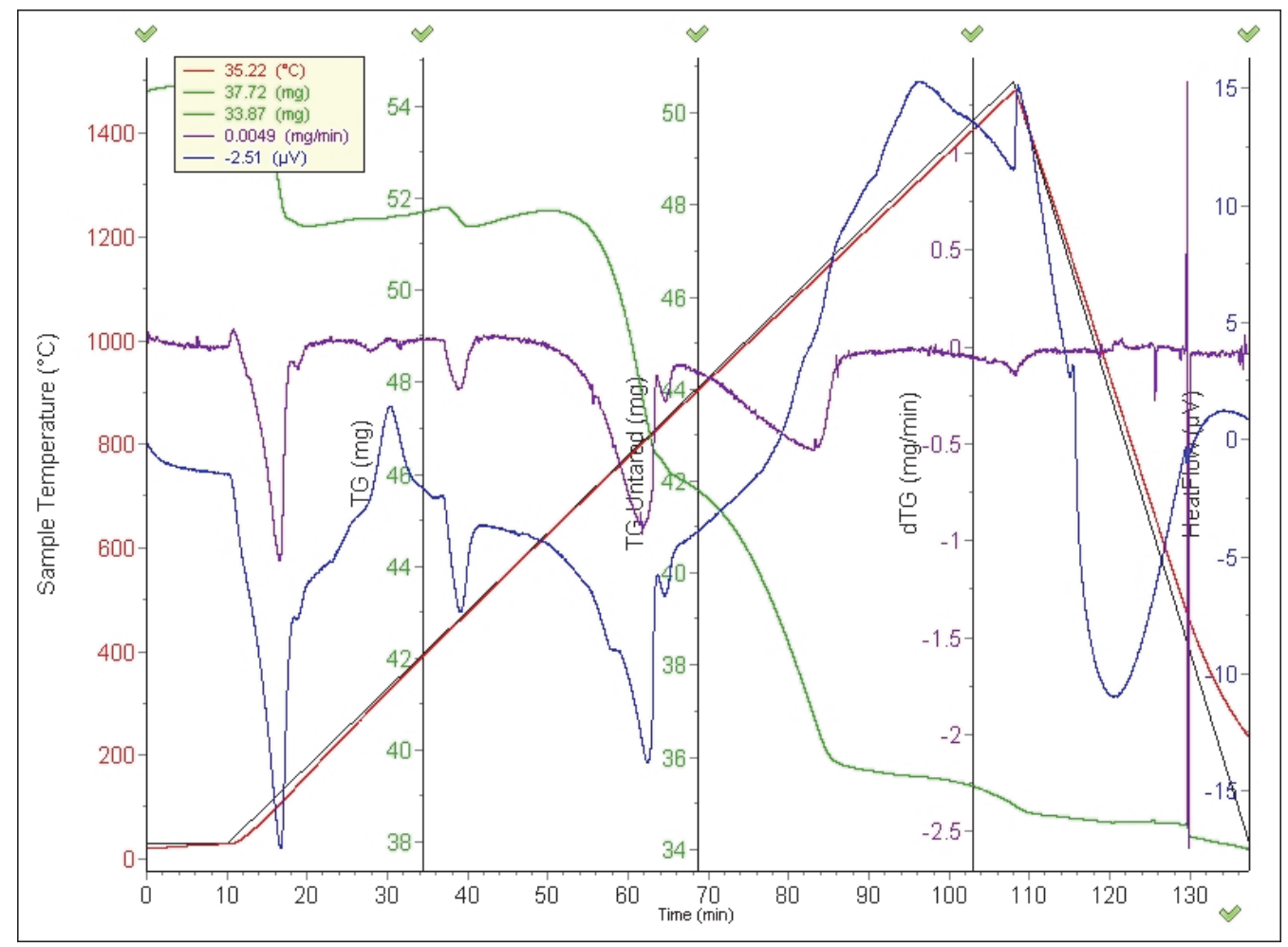

Figure 2. Derivatogram of the results of heat treatment of Aydarkul basalt samples

Thus, during the heat treatment of basaltic rocks of the Aydarkul deposit, the thermal decomposition of silicates and aluminosilicates, as well as carbonates occurs. During the heat treatment, the silicate components of basalts: pyroxenes, olivine's and plagioclases also undergo a structural change and interconversion products are created.

To obtain sufficient information and the interconversion of basalt during heat treatment, the IR spectroscopy method was used.

a)

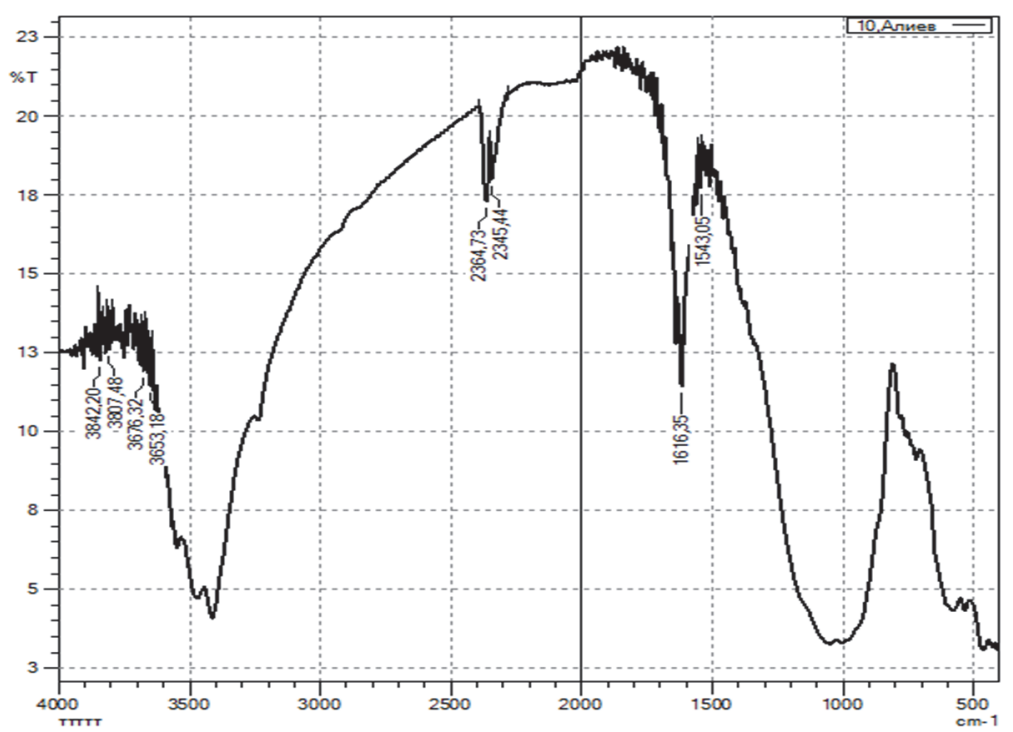


b)

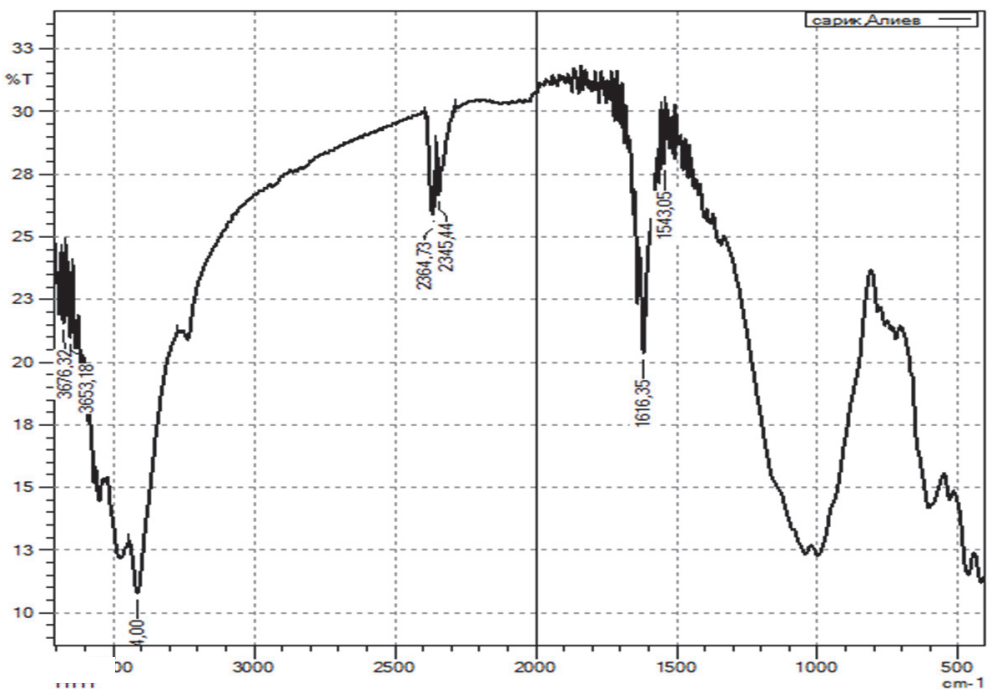

c)

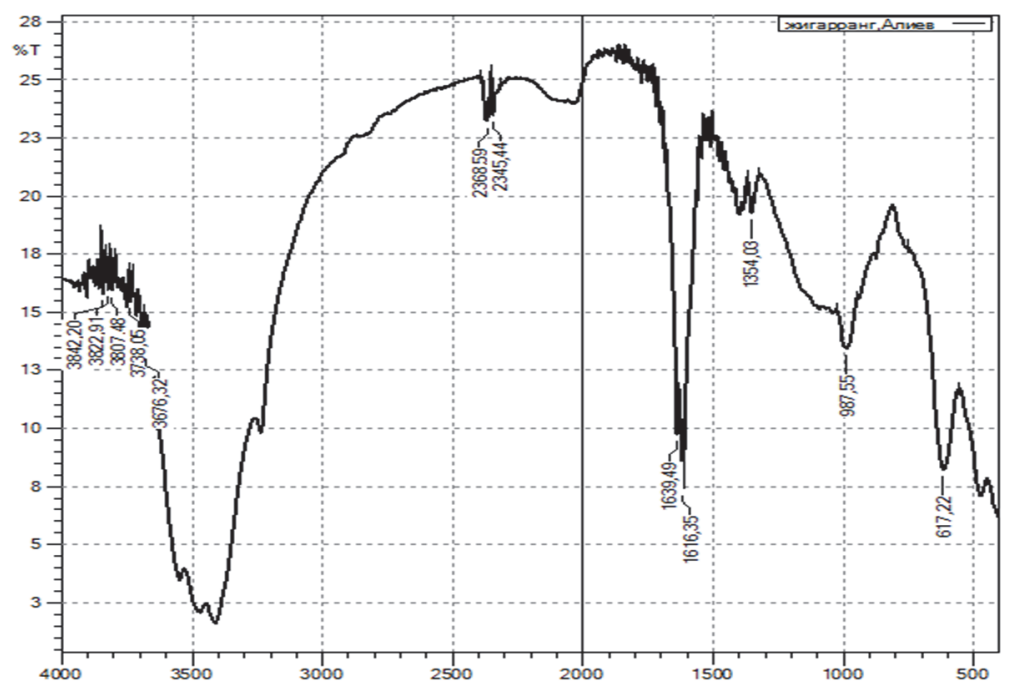

Figure 3. a, b \& c. IR spectra of Asmansai basalts

It is known that for the study of the intrinsic and material characteristics of rocks, it is widespread to study the functional groups containing various carbonates, silicates, and crystallization waters. Therefore, in this case, the infrared spectrometric (IR) method was used to identify the above factors in the process. [11-13].

\section{Results}

The results of an experimental study show that absorption bands are noticeable in the IR spectra. Such bands can especially be seen in the region of 756-800 sm-1, which are related to the deformation vibration of the Ms - OCO group disappears after heat treatment $(9000 \mathrm{C})$, which is confirmed by the decomposition of $\left(-\mathrm{CO}_{3}\right)$ carbonates. The absorption bands in the region of $1000 \mathrm{sm}-1$ show a wide spectrum related to the $v(\mathrm{CO}) \operatorname{Pr}(-\mathrm{OH}) v(-\mathrm{SiO})$ group.

The absorption bands in the region of $1639,1620 \mathrm{sm}-1$ are attributed to deformation vibrations $\delta\left(\mathrm{H}_{2} \mathrm{O}\right)$, which become short in the spectra after treatment. In the region of 3400 and $3600 \mathrm{sm}-1$ bands, the absorption corresponds to $\mathrm{OH}$ groups of water and mineral acid residues such as $\left[\mathrm{CO}_{4}\right]_{2^{-}},\left[\mathrm{SiO}_{4}\right]_{2^{-}}$and $\left[-\mathrm{Al}(\mathrm{OH})_{4}\right]-$.

Thus, the obtained infrared spectrum data asserts that during thermal treatment of basaltic rocks of the Aydarkul deposit they experience a change in the mineralogical composition.

The results of physical and chemical analyzes show that the initial samples of basalts of the Aydarkul deposit contain various carbonates, metals, hygroscopic and crystallized waters, which are completely removed from the 
composition of basalts during heat treatment at temperatures of 480 and $580^{\circ} \mathrm{C}$. In the future, the data presented give preferences for dry processing of basalts for the organization of production for various purposes.

Using tabular data, indicators of the chemical composition of the basalts of the Aydarkul deposit were identified, which are presented in Table 1. In addition, according to the derivatogram data, the endothermic effects of the thermal analysis process are observed. Especially at temperatures of $80 \div 240^{\circ} \mathrm{C}$, which respond to the decomposition or removal of clay impurities, hygroscopic waters present in the rock.

At a temperature of $520^{\circ} \mathrm{C}$, weak endo-effects and a slight increase in mass are observed, which corresponds to the interconversion of the component part of Aydarkul basalts. The presence of silicate and aluminosilicate clay rocks in the form of sludge remains in the basalts of the Aydarkul deposit was established by IR spectrometry.

Based on the research results, it was revealed that during the processing of Aydarkul basalts, it is necessary at the beginning to organize the cleaning of the rock from sludges and hydroxides in the form of a colloidal solution or suspensions using water washing and separation of sediments.

Based on the obtained results of the derivatogram study, the samples were subjected to heat treatment at temperatures: $100,300,500,700,900,100$ and $1200^{\circ} \mathrm{C}$. For heat treatment, a muffle burner was used. It was revealed that during heat treatment when the heating temperature reached $700-7500 \mathrm{C}$, reddish shades of crushed basalt mass were noticed. In the temperature limit of $800 \div 850^{\circ} \mathrm{C}$, a dark brown color stood out and at a temperature of $900 \div 950^{\circ} \mathrm{C}$ a dark color appeared.

In general, the obtained research results promote to the correct choice of the method of processing basalts to expand their scope by organizing the production of new different-colored industrial products. This is achieved by using a dry method of processing basalts, where there is no process of melting the rock, thereby reducing the technological costs of production of basalt products.

\section{References}

Kurbanov, A. A. (2016). Work out of rational technology of reprocessing different type of basalts of Uzbekistan" abstract of a dissertation for the degree of Doctor of Technical Sciences, Tashkent.

Kurbanov, A. A., \& Turaev, A. S. (2007). A brief overview of basalt and the resulting basalt materials. Scientific, technical and production journal Mountain Bulletin of Uzbekistan. Navoi, 3, 82-85.

Kurbanov, A. A., Abdurakhmonov, S. A., \& Turaev, A. S. (2010). Basics of processing of Kyzylkum basalts. Tashkent: Fan., 167s.

Kurbanov, A. A., Nurmatov, J. T., \& Rashidova, R., K. (2019). Comparative Analysis of the Physical and Chemical Properties of Uzbekistan's Basalts and Ways of Solutions to the Problems of Choice of Raw Processing Directions. Land Science, 1(1). https://doi.org/10.30560/ls.v1n1p59-62.

Kurbanov, A. A., Abduraxmanov, S. A., \& Muzaffarov, A. M. (2010). Definition method of filtration rate with the application of filter - Basalt wool. $11 \mathrm{p}$.

Nakomata, K. (1968). Infrared spectra of inorganic substances and coordination compounds. Ed."World"-1961. $200 \mathrm{sec}$ Bellamy. Infrared spectra of organic compounds. Ed. "World", 234, 118s.

Sattorov, L. Kh., \& Kurbanov, A. A. (2017). [Materials and Geoenvironment] The flexural stiffness and tension state of basalt filter. $R M Z-M \& G, 64,053-062$

Shuaib, H., \& Ahmad, G. C. (2004). Hoff Morris Schupack State-of-the-Art Report on Fiber Reinforced Concrete. Reported by ACI Committee. MCP., 544.

The report on research work. Budget topic A5-030. (2007). Develop effective technology for fire-resistant from local basalt raw materials and composite materials, $143 \mathrm{p}$.

Trebushko, O. P. (1984). Fundamental theory of elasticity and plasticity. Nauka, 318.

Vorobyov, A. E., Drebenstedt, K., Chekushina, T. V., \& Chekushina, E. (2007). Basalt: Innovative technologies of stone casting. Textbook. Moscow. RUDN, 200s.

\section{Copyrights}

Copyright for this article is retained by the author(s), with first publication rights granted to the journal.

This is an open-access article distributed under the terms and conditions of the Creative Commons Attribution license (http://creativecommons.org/licenses/by/4.0/). 